\title{
The Effect of Mnemonic Vocabulary Instruction on Reading Comprehension of Students
}

Parima Fasih, Siros Izadpanah*, Ali Shahnavaz

Department of English Language Teaching, Zanjan Branch, Islamic Azad University, Zanjan, Iran

Corresponding Author: Siros Izadpanah, E-mail: cyrosIzadpanah@yahoo.com

\section{ARTICLE INFO}

Article history

Received: November 19, 2017

Accepted: January 20, 2018

Published: May 01, 2018

Volume: 7 Issue: 3

Advance access: March 2018

Conflicts of interest: None

Funding: None

\begin{abstract}
The present article was an investigation of mnemonic vocabulary teaching to improve reading comprehension in the EFL classrooms. A major problem with the most of the past researches was that they paid no or little attention to the effects of using mnemonic strategies to improve reading comprehension. The purpose of this paper was to investigate how key word mnemonic vocabulary teaching can improve reading comprehension of the students. To this end, 360 third grade senior high school students from 6 senior high schools of Zanjan were selected through multistage cluster random sampling method and based on Cambridge placement test (2010), 345 students proved to be upper intermediate. A quasi-experimental design was used to determine the effects of a mnemonic vocabulary intervention on reading comprehension. In this article there were one control group ( $A, n=115)$, and two experimental groups $(B, n=115 ; C, n=115)$ all of which were male and there were selected randomly by the researchers. During one month in four weeks, every week in two thirty-minute session, group B received direct vocabulary instruction and group $\mathrm{C}$ received key word mnemonic instruction. The quantitative component of this article was comprised of the Unit Cloze test. In order to test the effects of Mnemonic Vocabulary Teaching on reading comprehension, the covariance analysis was employed and the results demonstrated that by eliminating the covariance factor of the pre-test, mnemonic vocabulary instruction improved the reading comprehension of the students. The use of keyword mnemonics as a means to differentiate instruction is an educational implication that can assist teachers seeking better student achievement outcomes.
\end{abstract}

Key words: Mnemonics, Mnemonic Vocabulary Instruction, Reading Compression, Traditional Vocabulary Instruction, Keyword.

\section{INTRODUCTION}

One of the most significant current discussions in the era of learning and teaching is mnemonic vocabulary techniques that plays a key role in learning the second or foreign language because it connects new learning to prior knowledge through the use of visual or acoustic cues (Abdullah, Mokhtar, Mohamed, Rawian \& Yahaya, 2017). The utilization of mnemonic dates back to 500 B.C and the word Mnemonic (pronounced as "ni-mon-iks") is derived from the Greek word "Mnemosyne" or "mnemon" which means mindful, alluding to the antiquated Greek goddess of memory (Pillai, 2017; Yates, 1966). The initially utilized mnemonic device was an earlier form of the current technique for loci and from that point forward, various devices have been produced (Amiryousefi \& Ketabi, 2011; Higbee, 1987; Pillai, 2017). Atkinson (1975) the pioneer of this issue believes that Mnemonic is an instructional strategy, techniques or devices intended to help students enhance their memory of vital information that includes teaching students to connect the new data to the information that they already know.
One important factor that affects the ease of L2 vocabulary learning involves committing the link between the word's form and its meaning to memory. Accordingly, the general picture of the mental vocabulary is one in which there are varieties of connections between some strong and weak words that we call the weak words "Mnemonics". (Amiryousefi \& Ketabi, 2011)

To help language learners tackle this difficulty, several researches about Mnemonic strategies have been proposed and used in vocabulary teaching and learning, such as the keyword method, the method of loci, the peg word system, grouping words, words according to semantic relationships, and analyzing the word's structure, studying its affixes and root (Dresler, Fernández, Greicius, Konrad, Müller, Shirer\& Wagner, 2017; Hunt \&Worthen, 2011). The basic types of mnemonic strategies rely on the use of key words, rhyming words, or acronyms. Teachers may develop mnemonic techniques or have students come up with their own. Also, more general researches on this issue were done by several researchers. Wei (2015), tested the effectiveness of the word 
part technique in comparison with the keyword method and self-strategy learning on university students and the results showed that the keyword method was inferior to the word part technique and self-strategy learning on the translation test format. Pillai (2017) provided information on how visual mnemonics, physical mnemonics and other mnemonic devices can be used in the ESL classroom to improve vocabulary, boost memory, enhance creativity and show that these mnemonic devices help increase the students' self-esteem as well as their learning and using these strategies to make them an independent learner was an ultimate goal of this study.

It is generally agreed that an important part of learning a foreign language is learning its vocabulary. One cannot read, write, speak or comprehend a language without knowing its words. According to Krashen (1993), when students travel, they do not carry grammar books but instead they carry dictionaries. Despite this importance, it seems that from about 1945 s to the late 1970 s and early 1980 s, almost all methods and approaches of language teaching gave vocabulary learning little or no prominence. To them vocabulary was secondary and could simply be left to take care of itself. In other words, little emphasis was placed on the acquisition of vocabulary and it was largely ignored by most researchers. Since then, however, because of the growing awareness of the importance of vocabulary and vocabulary learning, many studies tried to deal with different vocabulary learning strategies (e.g. Brown \& Perry, 1991; Fan, 2003; GU \& Johnson, 1996). Some of these vocabulary learning strategies achieved high levels of popularity at different times but then were replaced by other strategies which were claimed to be based on newer or more appealing ideas and theories. What is important here is that whatever these vocabulary learning strategies are, they have one thing in common; all of them, like any other kinds of strategies, are designed to facilitate the acquisition of new information. According to Nation (1982), "what learners do while studying words are more important than how motivated they are, how hard they work, how much time they spend and the number of repetitions of each word" (p. 25). This simple statement can vividly confirm the importance of applying strategies in learning new vocabulary items.

A wealth of research has documented the strength of the relationship between vocabulary and comprehension. So far, however, a major problem with all those researches was that they have not investigated the effects of using mnemonic strategies to improve reading comprehension, while this article had focused on the effectiveness of using mnemonic vocabulary strategies to Increase Reading comprehension in the EFL classrooms on 345 third grade senior high school students in Zanjan.

The issue of mnemonics (memory improvement techniques) in language learning has received some interest in research over 20 years ago but it was not a modern art. However, in the last 5 years, in particular, the topic has rekindled both theoretical and empirical research interest and yet there is no general agreement about to what extent teaching Mnemonic Vocabulary would improve students' reading comprehension.
Vocabulary learning was an important component, yet a challenging task in increasing the reading comprehension and also this issue requires the researchers to undertake investigations in order to find out more about their relationships. But the question is that what kinds of vocabulary learning strategies are more to the benefits of learners who think that the acquisition and recall of vocabulary is their greatest source of the problem in learning a foreign/second language. Although, up to now, the extensive number of studies have been conducted to answer the above question, to teach with what techniques or strategies is still a matter of considerable controversy. Therefore, still there appears to be a need for further investigation filling the remained gaps in this area.

The purpose of this article was to investigate the nature of Mnemonic vocabulary teaching and its effects on reading comprehension.

\section{REVIEW OF LITERATURE}

Since written material supplied one of the significant sources of knowledge, the capability to comprehend the content martials of a written text was vital in the pursuit of academic superiority. Regardless of the current sensitivity in writing at a discourse level, applied linguists have paid very little attention to the content vocabulary itself. If it was granted that everybody had the ability to read different texts and comprehend the content vocabulary, and also understand its meaning by different methods, why should it need research? However, writing forms a complex linguistic system, which was significant to all educated language users, and which must be achieved by all capable individuals in both the first language (L1) and second language (L2) (Cook, 2001). The significance of content vocabulary and understanding written texts required capable individuals to find out more about different vocabularies, which was difficult to master in English.

\section{Mnemonics}

Mnemonics (mnemonic devices or techniques) were mental aids that assisted us to remember distinctive sorts of items and information, for example, new word forms, names, historical dates, numbers, formulas, and various rules and lists. Regularly, they included recoding or breaking down formal segments of a target (to-be-remembered) item in a manner that makes these segments more familiar, abbreviated, or somehow less demanding to recall.

\section{Origins, History and Characteristics}

The term mnemonic had its origins in the ancient Greek term mnbmonikós, meaning "related to or of memory" (Mnemosyne was the goddess of memory in Greek mythology). The ancient Greeks had effectively recognized two different types of memory, one that was inborn and "natural" and another that was "artificial" and prepared by means of mnemonic techniques.

The history of keyword strategy came back to 1975 , when Atkinson the pioneer of this subject used it for teach- 
ing Russian vocabulary. Through this experimental study, the strategy expanded to use in schools, particularly to support students with learning disabilities in the 1980's and beyond (Atkinson, 1975).

Mnemonic devices can be arranged as "artificial," given the typically arbitrary connection between specific components of a given target item and how they were recoded.

\section{Mnemonic Instruction}

Mnemonic instruction links new information to earlier knowledge by utilizing the visual or acoustic cues (Kuder, 2017). many different strategies are utilized in Mnemonic instruction that are designed to enhance students' memory of new information. The keywords, peg words, and letter strategies work with various combinations and thought processes, but all of them can be utilized to manage facts and information. These distinctive methodologies can be found under different names, such as imagination, association, and location, however they all have a noteworthy impact in recalling and retrieving new information (Mastropieri \& Scruggs, 2017).

\section{Keyword Method}

Keyword strategies make use of concrete, similar sounding words to help students in the recall of new vocabulary words. For instance, for the term Cold War, the word "hold" could be utilized. This new keyword would be associated to an interactive representation that depicts the definition or concept and the keyword as they relate to one another (Marshak, Mastropieri, \& Scruggs, 2011; Piribabadi \& Rahmany, 2014). This type of strategy utilizes earlier knowledge to facilitate meaning of unknown words. Keywords are combined with interactive illustrations that make evident the meaning of the new word (Davoudi \& Yousefi, 2016; Lin, 2014).

\section{Internal Researches about Mnemonic Vocabulary Teaching and Reading Comprehension}

A wealth of Internal researches were done about Mnemonic Vocabulary Teaching and reading comprehension.

Davoudi and Taheri (2016), investigated the effect of the keyword method of vocabulary teaching on the learning and long term retention of vocabulary in a normal EFL classroom context. Fifty elementary EFL students were chosen and divided into experimental and control groups. The experimental group received mnemonic keyword vocabulary instruction and the control group received conventional memorization-based instruction of the same vocabulary items. For each group two post-tests administered, one test immediately after instruction and one test two weeks later. Paired and independent samples t-tests were run on the data and the results showed that participants in the keyword group outperformed the memorization group significantly in both their learning and retention of the vocabulary items. The results of the study approved the effectiveness of using mental links and images, through the utilization of mnemonic strategies, for the vocabulary learning and retention of elementary level EFL learners.
Keysan, Hasani and Zarei (2013), investigated the effects of selected presentation techniques including the keyword method, the peg word method, the loci method, argument mapping, concept mapping and mind mapping on L2 vocabulary comprehension and production. For this purpose, an example of 151 Iranian female students from a public pre-university school was chosen on the basis of accessibility. They were divided to six groups. Each group was randomly divided to one of the afore-mentioned treatment conditions. After the experimental period, two post-tests in multiple choice and fill-in-the-blanks formats were administered to estimate the participants' vocabulary comprehension and production. Two independent One-Way Anova procedures were utilized to investigate the acquired data. The results demonstrated that the differences among the impacts of the above-mentioned techniques were statistically important in both vocabulary comprehension and production. These findings can have implications for learners, teachers, and materials developers.

Azmi, Najmi and Rouyan (2016), examines the effectiveness of using mnemonic techniques in learning English vocabularies. This investigated the students' perspectives and point of view of the mnemonic technique in teaching and learning English vocabularies. The selected participants are students who are currently learning English subject in a primary school. Their English teachers instructed the students about English vocabulary with and without using the mnemonic technique. A set of questionnaire were designed by the researchers and administered for the students. The result received from the questionnaire demonstrated the effectiveness of using mnemonic techniques in learning English vocabularies as well as the students' response towards the technique.

Ashoori and Yazdani Moghadam (2015), attempted to find out the effectiveness of mnemonic devices as a memory strategy on the learners' vocabulary retention. For this purpose, 60 Iranian EFL acquirers at pre-intermediate level of language proficiency, were chosen and participated in this study. There was no limitation regarding their age. In order to homogenize the participants, the researcher implemented Preliminary English Test (PET) as a pretest. The participants were assigned into two groups of 30, experimental and control. Eighty pre-selected words through mnemonic devices was instructed for the experimental group, but the same vocabularies were instructed to the control group by traditional vocabulary instruction. To answer the first question, the mean scores of both experimental and control groups were compared on the immediate posttest. The result showed that through mnemonic devices are more influential than the traditional methods. To answer the second research question, the researcher analyzed the mean scores of the experimental group on the immediate and the delayed posttests. The result demonstrated that learners' delayed recognition of second language vocabulary is not influenced by the passage of time, it implies that words learned via mnemonics instruction were retrieved well both in the process of immediate and delayed retention. This study showed that memory strategies like mnemonics are of great application and importance in the process of short term and long term retention of EFL 
learners. Thus, mnemonic devices should be given prime attention by both EFL material developers and instructors as a potentially efficient technique for vocabulary instruction, acquisition, and long term retention at foreign language improvement.

Soleimani and Hajghani (2013) investigated the potential of implementing reading strategy instruction in raising learners' reading comprehension ability. This study was conducted using two groups of 90 female pre-university students in a pre-university center in Karaj in the academic year 2013. The results of the study demonstrated that while strategy training was effective for raising students' awareness of reading strategies, the reading strategy instruction was not effective to improve the students' reading performance.

Jalilehvand (2012) in her research examined the effects of text length and picture on reading comprehension. Seventynine first grade female students from three high schools in Iran were participated in this study. The participants were of the same level of proficiency. The researcher utilized two texts in this study. In fact, one of these two texts was a shortened version of the original text. The between subject design were used and participants were divided into four groups. Each group read a reading comprehension text under one of four conditions: 1) long text with picture, 2) long text without picture, 3) short text with picture, and 4) short text without picture. The reading comprehension texts were used along by 5 multiple-choice items and 10 true-false items. Although the participants performed better on the original text, the results of the analysis of variance (Anova) showed that length had no significant effect on reading comprehension of Iranian high school students. However, subjects performed better on texts with picture.

As it is evident in the above researches and many other researches that have been done in the field of reading and related topics and the effective factors that may led to enhancement of reading comprehension, but there are so many areas that have never been considered and discussed in detail. Such areas are observed as gaps of current studies of reading comprehension in this study. in the recent years there are few studies that investigated effects of other factors in improvement of reading comprehension but there are not many studies that are dealt with the effects of mnemonic vocabulary teaching on reading comprehension. Another issue is that most of the studies of reading comprehension were dealt with advanced and intermediate language learners at the same time and most of the results showed that the weak language learners do not know when, where and how to apply a specific strategy, but in this study the effects of mnemonic vocabulary teaching is investigated on only the upper intermediate students and the results are not related to the students' degree of knowledge and they are related to the effectiveness of the mnemonic vocabulary teaching. As it is demonstrated above most of the previous studies investigated the impact of mnemonic strategies instruction, encoding, pictorial and rehearsal strategies on vocabulary achievement and retention, the immediate and delayed information retrieval of vocabulary learning, the vocabulary improvement, the learning and long term retention of vocabulary, ESP vocabulary learning across proficiency levels, and as a way to boost vocabulary learning and recall. They also investigated the effect of direct vocabulary learning strategies on reading comprehension skill, on university students, and examined two different methods of vocabulary learning, namely the keyword method and context method to investigate their possible effects on receptive/productive vocabulary knowledge, retention, pronunciation and attitudes, to find out the effectiveness of mnemonic devices as a memory strategy on the learners' and retention of vocabulary over long term. They did all of those investigations on EFL elementary learners, in a normal EFL classroom context, on low-intermediate Iranian EFL learners on low intermediate level and on Fifth grade primary school students. But this study investigated the effects of Mnemonic and direct vocabulary teaching on reading comprehension and learning the content materials on the upper intermediate high school students, and also investigated the possible relationship between reading comprehension and mnemonic and direct vocabulary instruction. This study also asked teachers and students' attitudes toward these two teaching methods that in the previous studies little or no attention has been paid to these issues.

\section{External Studies about Mnemonic Vocabulary Teaching and Reading Comprehension}

Boyer (2017), determined if direct vocabulary instruction would lead to increased reading comprehension in third grade students who were English Language Learners reading below grade level. The Fountas and Pinnell Benchmark Assessment System, Third Edition were used as the measurement tool. This study used a pretest and posttest to measure growth in reading comprehension. After direct vocabulary instruction students' comprehension improved. This study made use of different strategies and techniques discovered through a review of literature on vocabulary acquisition. The more words that students know and understand through vocabulary instruction in the classroom, the more likely they are to comprehend what they have read. There are growing numbers of English Language Learners in classrooms across the country and hence research concentrating on the impact of vocabulary instruction on the reading comprehension of these students should go on.

Philips (2016), examined the effects of picture word pairing and semantic mapping strategies on the vocabulary understanding of second grade students. Fourteen second grade students were provided with an instructor created pretest on vocabulary words found in their story for the week. At that point, the instructor improved the usual vocabulary guideline with two visual strategies, picture word pairing and semantic mapping strategies. At long last, they were given a posttest to demonstrate how much they improved. Results showed that the intervention enhanced all participants' scores by $15 \%$. Eight out of fourteen had a score of over $80 \%$ on the posttest, recommending that the visual strategies helped the participants to learn vocabulary.

Nutt (2015), investigated about Mnemonic Vocabulary Instruction to Enhance Reading Comprehension in the Social Studies. Twenty-six sixth grade students and two teachers in two heterogeneous general education classes in a rural 
middle school were chosen to participate in a mixed methods study. A within-subjects crossover design were used for this study in which all of the students received the mnemonic vocabulary instruction at different times and it comprised the quantitative component of the research. The findings of this investigation give suggestions for teachers who work with a diverse student population in the general education environment. The results showed the positive effects of mnemonic vocabulary teaching on reading comprehension of the students.

Benge and Robbins (2009), investigated a strong relationship between vocabulary knowledge and reading comprehension and most agree that the larger one's base vocabulary, the better one's ability to comprehend text. 13 high school juniors and seniors whom they had educated as freshmen to test their degrees of consistency for the words we had learned in our supplementary SAT vocabulary program, were chosen. These (6 females and 7 males) former students, were selected utilizing a stratified purposeful sampling process (Gall, Gall, \& Borg, 2007), pulling a heterogeneous group enrolled in regular, honors and AP English III and English IV classes. Students who are capable readers continue to enhance their vocabularies while students who are struggling readers do not. In an effort to connect this gap, a secondary English teacher using action research methodology investigated keyword mnemonics as a way to actively engage her students in learning new vocabulary. The results showed that the keyword mnemonic method was efficient with her students.

Foorman, Petscher, Reed (2016), examined the contributions of vocabulary and spelling to the reading comprehension of students in grades 6-10 who were and were not classified as English language learners. Results demonstrated that vocabulary accounted for greater between-grade distinctions and unique variance (DR2 =.11-.31) in comprehension in comparison to spelling (DR2 $=.01-.09$ ). As regards, the contribution of spelling to comprehension was higher in the upper grade levels included in this cross-sectional analysis and functioned as a mediator of the effect of vocabulary knowledge at all levels. The direct effect of vocabulary was strong but lower in magnitude at each successive grade level from.58 in grade 6 to. 41 in grade 10 while the indirect result of spelling increased in magnitude at each successive grade level from.09 in grade 6 to.16 in grade 10. There were no significant differences between the language groups in the importance of the indirect effect, offering both groups of students depended more on both sources of lexical information in higher grades as compared to students in lower grades.

Alshehri (2014), provided support for the reading aloud strategy to improve reading comprehension. The study was conducted during the summer of 2014 in Saudi Arabia. 41 male students in the fifth grade participated in this study. The researcher clarified the reading aloud strategy to the participants to increase their reading comprehension. Then the students utilized the intended strategy during the reading lessons in order to increase their reading comprehension. This research study utilized the fifth grade textbook to decide if the use of the reading aloud strategy enhanced reading comprehension for students. This was measured by an examination of pre and post intervention reading comprehension tests. Moreover, a survey made and planned by the researcher for this study measured if students' enjoyment of reading increased through the use of the read aloud strategy. In conclusion, the researcher conducted observations and recorded field notes on students' behavior during reading lessons. As indicated by the outcomes, the reading aloud strategy demonstrated beneficial outcomes on the development and improvement of Saudi students' comprehension. The participants could associate their own experiences and personal knowledge with the daily texts to share their opinions and demonstrate a high level of understanding.

So far little attention has been paid to students' reading comprehension and the improvement of it by Mnemonic devices. Previous studies have focused more on the using pictures, vocabulary spelling, reading aloud strategies to help students understand the meaning of words or the sentence not to comprehend the whole passage. But this study investigated the effects of Mnemonic and direct methods on reading comprehension that lead to comprehend the whole passage. Most of the previous studies were about using mnemonics for accuracy and performance in solving multiplication facts and for vocabulary understanding by using picture word pairing and semantic mapping strategies, different mnemonic strategies like peg word, letter words, to see their effects on the motivation of the learners and in order to teach different words of different fields like algebraic and mathematic words, the impact of mnemonic devices on attainment and Recall in basic Knowledge Acquisition in different fields like nursing, but however there is not much focus on how keyword mnemonic instruction can improve reading comprehension of the upper intermediate students and understanding the content martials. Also this study found out teachers and students' attitude and idea altogether about using direct or Mnemonic vocabulary teaching, so far previous studies have focused more on students' results and they didn't ask their idea about Mnemonic or direct vocabulary teaching and this is what this study have done and investigated about students' and teachers' attitudes toward Mnemonics.

\section{METHOD}

\section{Participants}

The participants of this study were 360 third grade senior high school students in Zanjan. Zanjan province had 8 cities, from among these cities, Zanjan city was chosen. Zanjan city consisted of 2 districts that the district two was randomly chosen. In district 2 there were 433 schools that from among them senior high schools were randomly chosen. There were 47 senior high schools in district two that 24 of them were for boys and from among them, 8 senior high schools were non-profit. The third level students of 6 senior high schools included: Sama, Shams, Sourosh, kharazmi, Taha and Daneshmand junior high schools were randomly chosen. There were 3 third grade classes in each of them and two classes of each were randomly chosen for this study.

The statistical population of this study were 1712 third grade junior high school students in the second district in 
Zanjan. According to Cochron formula 349 participants were selected and in order to increase the accuracy and to have homogeneous groups $10 \%$ or 10 more participants were added and totally 360 students were participated in this study. Their age ranges were 15 to 16 . They were all male student. The type of sampling in this study was multistage cluster random sampling.

In order to guarantee the homogeneity of the participants of this study and to fulfill the objectives of the study; first, a Cambridge placement test (2010) by Cambridge University Press was distributed among all the students to determine their level of proficiency. The aim was to select those students with the upper intermediate level of proficiency. Out of 360 students, 345 students were proved to be upper intermediate. After that the Student's Consent Form was distributed among students in order to make them familiar with the processes of the current study (Appendix B). finally, in order to motivate the students for participating in this study, a notebook was provided for them as a gift.

\section{Pilot Study}

The Cold War Unit Cloze Pre-Test, Cold War Unit Cloze Post-Test, Civil Rights Unit Cloze Pre-Test, Civil Rights Unit Cloze Post-Test were piloted on 30 students with similar educational background in order to obtain the reliability for the test. The test-retest reliability of these tests with the one-week interval was. 82 which showed an acceptable reliability value, because tests that have scores with a reliability of. 80 or higher are sufficiently reliable for most investigation purposes (Gay, 1992, as cited in Chen, 2006).

\section{Instruments}

1. Cambridge placement test (2010) by Cambridge University Press

2. Cold War Unit Cloze Pre-Test

3. Cold War Unit Cloze Post-Test

4. Civil Rights Unit Cloze Pre-Test

5. Civil Rights Unit Cloze Post-Test

\section{Cambridge placement test}

To have a homogeneous group of participants, to neutralize any effect of proficiency level on participants' performance and to fulfill the objectives of the study, first, a Cambridge placement test (2010) by Cambridge University Press was distributed among all the student participants of this study in order to determine their level of proficiency. The aim was to select those students with the upper intermediate level of proficiency. Out of 345 students, 300 students proved to be upper intermediate.

\section{Unit cloze tests}

The Cloze assessments were researcher developed, and the validity and reliability were checked by three literacy researchers familiar with the use of Cloze reading assessments in Nutt's investigation (2015). These tests were expository text related to the content. For the pre-test, content specific information was included within the text. In each paragraph, three underlined words, names or titles were interspersed. Students were required to circle the correct answer. Thus, each correct answer was given one point, and incorrect or missing answers did not receive any points. The Cloze post-assessment was similar to the pre-assessments with one exception: instead of having three underlined words to circle, a blank was in place and a word bank was provided; students were directed to fill in the blank with the correct word.

\section{Procedure}

In this study, two classes of every six senior high schools (Shams, Sorosh, Kharazmi, Taha, Daneshmand and Sama) were chosen and assigned them randomly into three groups, one control group (A) and two experimental groups (B and C). The English teachers of this six senior high schools were from among teacher participants of this study and the researchers learned them the teaching procedures of Mnemonic and direct methods for this study. The teaching materials covered during this intervention was the Cold War era and the Civil Rights movement vocabularies that were validated by Nutt (2015). Then, by the help of the English teachers and the researchers, during one month in four weeks, every week in two thirty-minute session, students in experimental group B received direct vocabulary instruction $(n=115)$ and students in experimental group $\mathrm{C}$ received the Key word mnemonic instruction $(n=115)$ and how to use this technique in reading. For all of the classes the same pre-tests were used to inform and guide the instruction, focusing on the areas of weakness demonstrated by the students on the assessment. After the students took the pre-tests, results were used to guide content instruction, through the use of PowerPoint slides for all of the experimental groups and they participated in whole group instruction.

\section{Instructional Procedure: Control Group}

During this four-week study, the control group A didn't not receive treatment by the researchers and was then used as a benchmark to measure the other tested subjects' treatment. Like other participants of this study, they were provided with pre- post tests and the results were used to compare the participants of groups $\mathrm{A}, \mathrm{B}$ and $\mathrm{C}$ and to examine the effects of using key word and direct method instruction on reading comprehension and content vocabulary learning.

\section{Instructional Procedure: Experimental Group (Key Word Mnemonic Instruction).}

In experimental group $\mathrm{C}$, the ELF teachers of each classes by the help of the researchers and Key word mnemonic instruction introduced vocabulary words each session. In key word mnemonic instruction, there were some cards that they were first presented as a PowerPoint presentation with the teacher introducing each vocabulary word along with the illustration that connected pictorial images of concrete keywords with an action that represented the vocabulary word's definition 
(Fontana, Mastropieri \&Scruggs, 2007). After that these cards were printed and given to the students for further studies. Students were directed to take notes in their notebooks, and to ask questions or pose comments. Before the initial mnemonic strategy instruction, at the beginning of class, teachers provided content information with a discussion of material covered previously.

The focus of the Mnemonic vocabulary instruction was students learning key words in order to understand and learn about the meanings of the words in a reading.

\section{Instructional procedure: Experimental group (direct vocabulary instruction).}

In the experimental group (B), different valid dictionaries like Oxford English Dictionary were used and the exact meaning of the words were introduced for the participants. In this condition, students were encouraged to ask questions, and to seek clarification on specific points. PowerPoint presentations was provided for the day's content focus with students writing notes in their notebooks. A list of the words to be taught are presented in the form of a pamphlet for the participants. Difficult vocabulary was highlighted during traditional vocabulary instruction in the word list. Before the initial direct instruction, at the beginning of class, teachers provided content information with a discussion of material covered previously.

\section{RESULTS AND DISCUSSION}

Does the use of a mnemonic vocabulary instruction improve reading comprehension for students?

To analyze the data collected from these participants, SPSS Statistic 24 software was used. The hypothesis of this research question was the use of a mnemonic vocabulary intervention will improve reading comprehension for students. In order to test this hypnosis covariance analysis was employed. Covariance analysis (ANCOVA) was a comprehen- sive mode of variance analysis in which it was possible to compare the means of one or more groups and estimate one or more independent variables and also to extract the effect of one or more intervening variables, covariance, or covariate from the equation. In other words, covariance analysis was a statistical method that allowed the investigation of the effect of an independent variable on the dependent variable while eliminating the effect of another variable. The best use of covariance analysis was when participants were randomly placed at one of the independent variable levels and the Covariate variable was measured before using the analysis not afterwards because if it was measured subsequently it may change in the exposure of the independent variable. So, covariance analysis was used to compare students' performance on Cloze pre and post-test (pre and post UC test) scores in the mnemonic versus control groups.

Descriptive statistics of reading comprehension scores in the control and experimental group, in the pre-test and posttest, was demonstrated in the Table 4.1.

\section{Normality of the Scores}

Afterwards, one-sample Kolmogorov-Smirnov tests were conducted in order to check the normal distribution of the data. The results were demonstrated in the Table 4.2 and 4.3.

Considering the Sig values obtained in the Table 4.2 and Table 4.3, all of which were more than 0.05 , H0 that was the normality of the variables in the pre and post-test scores at the significance level of 0.05 was accepted.

\section{Homogeneity of the Variances}

In this study, Levene's test was an inferential statistic used to assess the equality of variances for a variable calculated for two or more groups. Some common statistical procedures assume that variances of the population from which different samples were drawn were equal. In this research the Levene test was used to check the homogeneity of the

Table 4.1. Descriptive statistics of pre and post UC test scores in the control and experimental group

\begin{tabular}{lccccc}
\hline Descriptive statistics & & & & & \\
\hline Group & N & Minimum & Maximum & Mean & Standard deviation \\
\hline Cortrol & & & & & \\
$\quad$ Pre.UC & 115 & 0.00 & 6.00 & 2.2348 & 1.67191 \\
Post.UC & 115 & 0.00 & 6.50 & 2.1348 & 1.64946 \\
$\quad$ Valid N (listwise) & 115 & & & & 1.51916 \\
Expriment & & & 5.00 & 2.3217 & 1.14339 \\
Pre.UC & 115 & 0.00 & 18.00 & 15.3339 & \\
Post.UC & 115 & 12.00 & & & \\
$\quad$ Valid N (likewise) & 115 & & & & \\
\hline
\end{tabular}

Table 4.2. The normality of the pre-tests scores in control and experimental groups

\begin{tabular}{llcl}
\hline Variables & Sig & Decision & Results \\
\hline Reading comprehension scores of control group & Acceptance of H0 & 0.18 & Distribution is normal \\
Reading comprehension scores of experimental group & Acceptance of H0 & 0.2 & Distribution is normal \\
\hline
\end{tabular}


variances and the results were presented in the Tables 4.4 and 4.5.

Considering the Sig values obtained in Tables 4.4 and 4.5 , all of which were more than 0.05 , the $\mathrm{H} 0$ that was about homogeneity of the variances at the significance level of 0.05 was accepted and therefore the assumption of the homogeneity of the variances of the participants in the pre and post-tests scores were accepted with the $5 \%$ level of error.

\section{Covariance Running Before Beginning the Study}

This presupposition was followed and pre-test has been performed before the implementation of the independent variable (Mnemonic vocabulary instruction).

\section{Homogeneity of Regression Slope}

To analyze the homogeneity of regression slope, the $\mathrm{F}$ value was calculated between covariance and independent variables the results which were presented in the Table 4.6 showed that this index was significant ( $\mathrm{Sig}>0.05)$.

Considering the Sig values obtained in Table 4.6, all of which were more than 0.05 , H0 namely the assumption of regression line slope homogeneity between covariance and independent variable was accepted at the significance level of 0.05 .

\section{The Linearity of the Correlation of Covariance Variable and Independent Variable}

In order to analyze the linearity of the correlation of the covariance variable and independent variable, the $F$ value of the covariance variable were calculated. the F value was calculated between covariance and independent variables the results which are presented in the Table 4.7 showed that this index was significant ( $\mathrm{Sig}>0.05)$.

Considering the Sig value obtained in Table 4.7, all of which were less than 0.05 , the $\mathrm{H} 1$ namely the assumption of linearity of the correlation between covariance and independent variable was accepted at the significance level of 0.05 .

\section{Hypothesis}

For data analysis of this hypothesis, as it is mentioned before, covariance analysis was used. Also, the necessary assumptions for analysis of covariance were investigated and these assumptions were existing. The results of covariance analysis were demonstrated in the Tables 4.8.

As was shown in the Table 4.8, the value of $\mathrm{F}$ in covariance analysis for meaningful comprehension of comprehension scores was significant and the $\mathrm{H} 0$ was rejected and therefore it can be concluded that there was a significant difference between the mean of two groups (control group and experimental group) in the post test after the adjustment of the Pre-test scores. According to the Table 4.1, the mean of control group in the pre-test was 2.23 and in the post test was 2.13 , while the mean of experimental group in the pretest was 2.32 and in the posttest was 15.33 . Considering the significant difference between the post-test scores in the control and experimental groups, it was concluded that by eliminating the covariance factor of the pre-test, Mnemonic vocabulary instruction improved the reading comprehension of the students.

\section{DISCUSSION}

The research question for this investigation was "Does the use of a mnemonic vocabulary intervention within third grade senior high school students at the upper intermediate level improve reading comprehension for students?"

In the present investigation, Students in experimental $\mathrm{C}$ received the key word mnemonic instruction $(n=115)$ and how to use this technique in reading. Students in comparison to the control group demonstrated gains on all measures from pre-test to post-test and all students demonstrated im-

Table 4.3. The normality of the post-tests scores in control and experimental groups.

\begin{tabular}{llcl}
\hline Variables & Sig & Decision & Results \\
\hline Reading comprehension scores of control group & Acceptance of H0 & 0.13 & Distribution is normal \\
Reading comprehension scores of experimental group & Acceptance of H0 & 40.2 & Distribution is normal \\
\hline
\end{tabular}

Table 4.4. Homogeneity of variance between control and experimental groups in pre-test

\begin{tabular}{lcll}
\hline Variables & Sig & Decision & Results \\
\hline Reading comprehension scores & 0.115 & Acceptance of H0 & Acceptance of the homogeneity of variances \\
\hline
\end{tabular}

Table 4.5. Homogeneity of variance between control and experimental groups in post-test

\begin{tabular}{llll}
\hline Variables & Sig & Decision & Results \\
\hline Reading comprehension scores & 0.18 & Acceptance of H0 & Acceptance of the homogeneity of variances \\
\hline
\end{tabular}

Table 4.6. Regression Slope homogeneity test between covariance and independent variable

\begin{tabular}{llll}
\hline Variables & Sig & F test statistics & Results \\
\hline Reading comprehension scores & 0.59 & 0.63 & Acceptance of the regression slope homogeneity \\
\hline
\end{tabular}


Table 4.7. The test of linearity of the correlation of covariance and independent variable

\begin{tabular}{lccl}
\hline Variables & Sig & F test statistics & Results \\
\hline Reading comprehension scores in pre-test & 0.000 & 131.33 & Acceptance of the linearity of the correlation \\
\hline
\end{tabular}

Table 4.8. The results of covariance analysis

\begin{tabular}{|c|c|c|c|c|c|}
\hline \multicolumn{6}{|c|}{ Tests of between-subjects effects } \\
\hline \multicolumn{6}{|c|}{ Dependent variable: Post.UC } \\
\hline Source & Type III sum of squares & df & Mean square & $\mathbf{F}$ & Sig. \\
\hline Corrected model & $10185.781^{\mathrm{a}}$ & 2 & 5092.891 & 3974.203 & 0.000 \\
\hline Intercept & 4249.044 & 1 & 4249.044 & 3315.713 & 0.000 \\
\hline Pre.UC & 168.301 & 1 & 168.301 & 131.333 & 0.000 \\
\hline Group & 9939.184 & 1 & 9939.184 & 7755.977 & 0.000 \\
\hline Error & 290.898 & 227 & 1.281 & & \\
\hline Total & 28023.110 & 230 & & & \\
\hline Corrected total & 10476.679 & 229 & & & \\
\hline
\end{tabular}

a. $\mathrm{R}$ squared $=0.972$ (Adjusted R Squared $=0.972$ )

provements. The overall findings determined that there are significant differences in student performance for condition on the pre- and post-tests on both the Cold War and Civil Rights vocabulary tests.

Previous research on the effectiveness of content vocabulary acquisition, and reading comprehension has provided a sound argument for teaching vocabulary to improve reading comprehension. The current investigation was in line with the previous researches on use of the mnemonic strategy instruction in the classroom area.

For example, Jangid, Swadia and Sharma (2017) investigated the effectiveness of mnemonics on thinking pattern of Children with Learning Disability and with the help of purposive sampling technique, 30 children diagnosed with learning disorder in reading and writing are participated in this study and they were divided into experimental and control groups. The research was done over a period of three months. The first group was experimental group in which a meeting with the teachers was conducted before treatment initiation to review the training procedure. The test of thinking Strategies developed by Mehta, (2011) was utilized in order to quantify the thinking strategies among children with learning disability. The five primary teachers were provided a formal training of ten days and training notebook containing mnemonic instruction manual. The instruction manual was provided by the investigators according to their regular classroom curriculum with the assistance of their teachers. Findings demonstrated that mnemonic instructions have greater effects on the development and enhancement of memory, reasoning, and concept and problem solving skills of learning disabled children in comparison to regular classroom teaching instructions. The results showed that students receiving the mnemonic instruction scored significantly higher than the students who did not receive the instruction. So the current study extends the Jangid, Swadia and Sharma study, as the researcher delivered the instruction in an individualized setting. In the current study, the classroom teachers and the researcher delivered the mnemonic vocabulary instruction for the group $\mathrm{C}$ as the key word mnemonic group as opposed to researcher delivered instruction.

Additionally, Brigham, Scruggs, and Mastropieri (1995) used mnemonics within the social studies curriculum. Students were instructed the details of American Revolution battles and their corresponding location. Seventy-two middle school students with disabilities participated in this study. Students in the treatment condition recalled significantly more facts. The current study extends this investigation as it takes place in a general education classroom. The current investigation also extends the method of instruction. In Brigham et al.'s study, the researcher provided the instruction. In the current study, the classroom teachers and the researcher provided the mnemonic vocabulary instruction. Finally, students in both studies and in the mnemonic condition demonstrated gains in scores on all post-tests.

Finally, Fontana, Scruggs, and Mastropieri (2007) broadened the study using mnemonic strategy instruction in the class room setting. Mnemonic strategies and direct delivered for Four inclusive world history classes at the high school level to 59 students. The result demonstrated that students had significantly higher scores on a cumulative multiple-choice test on content using mnemonic strategies in comparison to the direct instruction. The current study was similar to Fontana and colleagues' investigation as the classroom teachers delivered social studies content. However, the current study extended this research, as the general education teachers and the researcher delivered the mnemonic instruction in the inclusive classrooms. Additionally, Fontana and colleagues reported that the mean scores by student group were not significant, with the exception of the ESL subgroup. In the current investigation, increased mean scores for all students on the post-tests were achieved.

The practical significance of this research question was to use mnemonic vocabulary technique as a way to improve reading comprehension of the students in the third level of high school and also in can be used for different levels in different academic places. 


\section{CONCLUSION}

This paper was an investigation about using mnemonic vocabulary instruction to improve reading comprehension and the goal of this paper was to investigate how key word mnemonic vocabulary teaching can improve reading comprehension of the students. Results showed that The use of a mnemonic vocabulary instruction improved the reading comprehension of the third grade senior high school students and they were very satisfied to use this technique for learning new materials in order to enhance their reading comprehension in the future. Also students showed greater gains on assessments during the mnemonic condition. More importantly, mnemonic vocabulary instruction increased student engagement and motivation toward new vocabularies and they showed greater gains on the assessments.

\section{REFERENCES}

Atkinson, R. C. (1975). Mnemotechnics in second-language learning. American psychologist, 30(8), 821-828. DOI: http://dx.doi.org/10.1037/h0077029

Amiryousefi, M., \& Ketabi, S. (2011). Mnemonic Instruction: A Way to Boost Vocabulary Learning and Recall. Journal of Language Teaching \& Research, 2(1), 178182. DOI:10.4304/jltr.2.1.178-182

Alshehri, M. (2014). Improving reading comprehension for Saudi Students by using the Reading Aloud Strategy (Doctoral dissertation), Retrieved time (accessed 10.2.2017)

Ashoori, P., \& Moghadam, M. (2015). The effect of instructing mnemonic devices on immediate versus delayed vocabulary retention. International Journal of Language Learning and Applied Linguistics World, 8(1), 87-102.

Azmi, M. N. L., Najmi, M. H. S. M., \& Rouyan, N. M. (2016). A Case Study on the Effects of Mnemonics on English Vocabulary. International Journal of Applied Linguistics and English Literature, 5(7), 178-185. DOI:10.7575/aiac.ijalel.v.5n.7p.178

Brown, T. S., \& Perry, F. L. (1991). A comparison of three learning strategies for ESL vocabulary acquisition. Tesol Quarterly, 25(4), 655-670. DOI: 10.2307/3587081

Boyer, K. (2017). The Relationship Between Vocabulary and Reading Comprehension in Third Grade Students Who Are English Language Learners and Reading Below Grade Level. (Masters Thesis). Retrieved time (assessed 21.8.2017)

Benge, C., \& Robbins, M. E. (2009). Using keyword mnemonics to develop secondary students' vocabularies: A teacher's action research. Journal of Language and Literacy Education, 6(1), 93-104.

Brigham, F. J., Scruggs, T. E., \& Mastropieri, M. A. (1995). Elaborative maps for enhanced learning of historical information: Uniting spatial, verbal, and imaginal information. The Journal of Special Education, 28(4), 440-460. DOI: https://doi.org/10.1177/002246699502800404

Chen, Y. M. (2006). The effect of keyword method on English vocabulary long-term retention of elementary school students in Taiwan. Unpublished Master Thesis. Department of Applied English, Southern Taiwan University. Retrieved time (assessed 3.2.2017)
Davoudi, M., \& Yousefi, D. (2016). The Effect of Keyword Method on Vocabulary Retention of Senior High School EFL Learners in Iran. Journal of Education and Practice, 7(11), 106-113.

Dresler, M., Shirer, W. R., Konrad, B. N., Müller, N. C., Wagner, I. C., Fernández, G., \& Greicius, M. D. (2017). Mnemonic training reshapes brain networks to support superior memory. Neuron, 93(5), 1227-1235. DOI: http://dx.doi.org/10.1016/j.neuron.2017.02.003

Fan, M. Y. (2003). Frequency of use, perceived usefulness, and actual usefulness of second language vocabulary strategies: Astudy of Hong Konglearners. The ModernLanguage Journal, 87(2), 222-241. DOI: 10.1111/1540-4781.00187

Fontana, J. L., Scruggs, T., \& Mastropieri, M. A. (2007). Mnemonic strategy instruction in inclusive secondary social studies classes. Remedial and Special Education, 28(6), 345-355. DOI: https://doi.org/10.1177/07419325 070280060401

Gu, Y., \& Johnson, R. K. (1996). Vocabulary learning strategies andlanguagelearningoutcomes. Languagelearning, 46(4), 643-679. DOI: 10.1111/j.1467-1770.1996.tb01355.x

Higbee, K. L. (1979). Recent research on visual mnemonics: Historical roots and educational fruits. Review of Educational Research, 49(4), 611-629. DOI: https://doi. org/10.3102/00346543049004611

Jangid, N., Swadia, H., \& Sharma, D. (2017). Effectiveness of Mnemonic Instructions on the Thinking Strategies of Children with Learning Disability. Journal of Disability Management and Rehabilitation, 2(1), 22-27.

Jalilehvand, M. (2012). The effects of text length and picture on reading comprehension of Iranian EFL students. Asian Social Science, 8(3), 329-337. DOI: http://dx.doi. org/10.5539/ass.v8n3p329

Krashen, S. D. (1993). The Case for Free Voluntary Reading. Canadian Modern Language Review, 50(1), 72-82.

Kuder, S. J. (2017). Vocabulary Instruction for Secondary Students with Reading Disabilities: An Updated Research Review. Learning Disability Quarterly, 0731948717690113,40(3),155-164. DOI: https://doi. org/10.1177/0731948717690113

Lin, G. (2014). Using Mnemonic Keyword Method to Help Taiwanese Children Learn English Vocabulary,2(1), 1727. DOI: $10.4304 /$ jltr.2.1.178-182

Mastropieri, M. A., \& Scruggs, T. E. (2017). The inclusive classroom: Strategies for effective differentiated instruction. South Carolina: Pearson.

Marshak, L., Mastropieri, M. A., \& Scruggs, T. E. (2011). Curriculum enhancements in inclusive secondary social studies classrooms. Exceptionality, 19(2), 61-74. DIO: http://dx.doi.org/10.1080/09362835.2011.562092

Mokhtar,A.A., Rawian, R. M., Yahaya, M. F., Abdullah, A., \& Mohamed, A. R. (2017). Vocabulary learning strategies of adult ESL learners. The English Teacher, 38(12), 133 $-145$.

Nation, I. P. (1982). Beginning to learn foreign vocabulary: $A$ review of the research. RELC journal, 13(1), 14-36. DOI: https://doi.org/10.1177/003368828201300102

Nutt, K. T. (2015). Mnemonic Vocabulary Instruction to Enhance Reading Comprehension in the Social Studies 
Classroom (Doctoral dissertation). Retrieved time (assessed 3.12.2017).

Piribabadi, A., \& Rahmany, R. (2014). The Effect of the Keyword Method and Word-list Method Instruction on ESP Vocabulary Learning. Journal of Language Teaching \& Research, 5(5), 1110-1115. DOI:10.4304/jltr.5.5.1110-1115

Phillips, M. (2016). The Effects of Visual Vocabulary Strategies on Vocabulary Knowledge. Thesis, retrieved time (assessed 3.12.2017)

Pillai, N. R. (2017). Using mnemonics to improve vocabulary, boost memory and enhance creativity in the ESL classroom. The English Teacher, 38(22), 62 -83.

Reed, D. K., Petscher, Y., \& Foorman, B. R. (2016). The contribution of vocabulary knowledge and spelling to the reading comprehension of adolescents who are and are not English language learners. Reading and writing, 29(4), 633-657.

Soleimani, H., \& Hajghani, S. (2013). The effect of teaching reading comprehension strategies on Iranian
EFL pre-university students' reading comprehension ability. International Journal of Applied and Basic Sciences, 5(5), 594-600.

Taheri, A. A., \& Davoudi, M. (2016). The effect of the keyword method on vocabulary learning and long-term retention. International Journal of Language and Linguistics, 3(1), 114-125.

Wei, Z. (2015). Does teaching mnemonics for vocabulary learning make a difference? Putting the keyword method and the word part technique to the test. Language Teaching Research, 19(1), 43-69. DOI: https://doi. org/10.1177/1362168814541734

Yates, F. (1966). The Art of Memory. London. UK: Routegeand Kegan Paul Ltd.

Zarei, A. A., Hasani, M. T., \& Keysan, F. (2013). Vocabulary teaching: mnemonic and mind mapping techniques in focus. Lambert Academic Publishing. 978-3-65938989-4. Retrieved October 3, 2013 from http://www.090ad_1367322124key.pdf 